\title{
Chordoid Meningioma
}

\author{
-Case Report-
}

\author{
Takashi MitsuHASHI, Shinsuke ONO, Tadashi INOHARA, \\ Takashi Отомо, Ауа AOKI, and Yasuyuki UEKI
}

Department of Neurosurgery, Tokyo Metropolitan Hiroo General Hospital, Tokyo

\begin{abstract}
A 69-year-old female presented with a de novo lesion detected incidentally. Computed tomography demonstrated an isodense mass in the left parietal convexity with peritumoral edema, with homogeneous enhancement by contrast medium. Magnetic resonance imaging showed the left parietal convexity tumor as isointense on $T_{1}$-weighted imaging and homogeneously hyperintense on $T_{2}$-weighted imaging, with homogeneous enhancement and dural tail sign after intravenous administration of gadoliniumdiethylenetriaminepenta-acetic acid. The tumor was totally removed. The histological diagnosis was chordoid meningioma. Combined immunohistochemical staining was helpful to differentiate chordoid meningioma from other chordoid neoplasm.
\end{abstract}

Key words: chordoid meningioma, brain tumor

\section{Introduction}

Chordoid meningioma was first described as a meningioma with a peculiar myxoid-chordoid pattern in 1988, associated with young patients, Castleman's disease, and polyclonal lymphoplasmacellular infiltration with lymph follicles and germinal centers. ${ }^{11)}$ The first known case was reported in $1980 .^{3,7)} \mathrm{A}$ large adult series of chordoid meningioma without systemic disease has been reported.4)

The 2000 World Health Organization (WHO) classification of central nervous system tumors included chordoid meningioma as one of 15 subtypes of meningiomas. The 1993 WHO classification of central nervous system tumors accepted lymphoplasmacyte-rich meningioma and chordoid meningioma as variants of meningioma. Chordoid meningioma corresponds to WHO grade II because of its more aggressive clinical behavior, and is recommended for regular follow up after surgery. ${ }^{12)}$ Meningiomas account for $13-26 \%$ of all primary intracranial tumors. ${ }^{13}$ Chordoid meningioma is a very rare subtype of meningioma with an incidence of $0.5 \%$ or less of all meningiomas. ${ }^{4)}$

We treated a 69-year-old woman with chordoid

Received January 20, 2005; Accepted August 1, 2005 meningioma, which was identified with immunohistochemical staining.

\section{Case Report}

A 69-year-old female suffered an episode of subarachnoid hemorrhage due to ruptured vertebral artery-posterior inferior cerebellar artery aneurysm in 1994. She underwent lateral suboccipital craniotomy and aneurysm clipping. Right ventriculoperitoneal shunting was performed for secondary hydrocephalus. She was discharged without neurological deficits (Karnofsky performance status score $100 \%$ ). Since then she had been followed up for approximately 10 years in our outpatient department. Computed tomography (CT) has been regularly performed once a year.

Follow-up CT detected a de novo lesion in 2004 and she was admitted for further study and treatment. On admission, neurological examination found no deficits. Routine laboratory tests showed hemoglobin, mean corpuscular volume, and mean corpuscular hemoglobin values were $12.6 \mathrm{~g} / \mathrm{dl}, 92.4$ fl, and $30.9 \mathrm{pg}$, respectively. Total protein, albumin, and globulin values were $7.5 \mathrm{~g} / \mathrm{dl}, 4.5 \mathrm{~g} / \mathrm{dl}$, and 2.6 $\mathrm{g} / \mathrm{dl}$, so the albumin-globulin ratio was 1.7 (reference range 1.3-2.2). There was no laboratory finding suggesting systemic disease such as hematologic abnormality or dysgammaglobulinemia. 

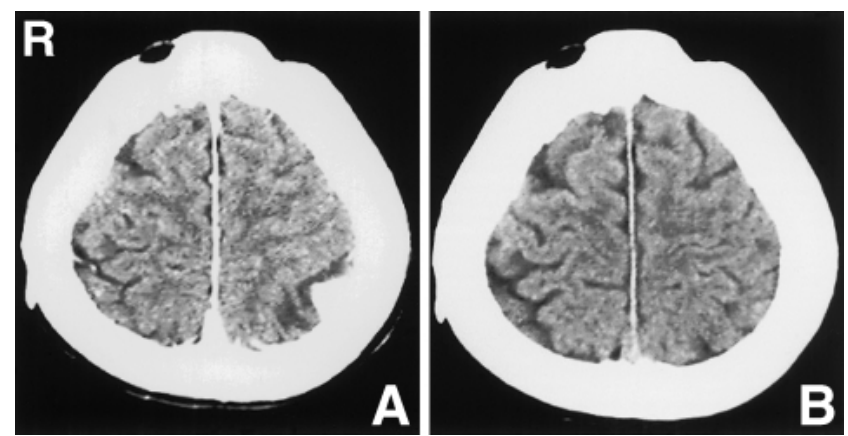

Fig. 1 Computed tomography scans showing homogeneous enhancement by contrast medium of a de novo lesion in the left parietal lobe with peritumoral edema (A), which was apparently not present in the absence of contrast medium 1 year previously (B).

CT showed an isodense mass in the left parietal lobe with homogeneous enhancement by contrast medium, and perifocal edema (Fig. 1). Magnetic resonance (MR) imaging showed the corresponding tumor as homogeneously isointense on $\mathrm{T}_{1}$-weighted imaging and homogeneously hyperintense on $\mathrm{T}_{2}$ weighted imaging, with homogeneous enhancement after intravenous administration of gadoliniumdiethylenetriaminepenta-acetic acid (Gd-DTPA). Axial and coronal $\mathrm{T}_{1}$-weighted $\mathrm{MR}$ imaging with Gd-DTPA showed thick and wide "dural tail sign" around the tumor attachment. Associated peritumoral edema appeared as hyperintense on $\mathrm{T}_{2}$-weighted imaging (Fig. 2). The preoperative diagnosis was malignant meningioma because of the irregular tumor margin, widespread perifocal edema based on the tumor size, and the progressive growth.

Tumor resection was performed via a left parietal craniotomy. The well-defined and yellowish gray tumor attached to the dura mater was totally resected (Simpson's grade I). Histological examination showed the tumor included cell islands consisting of fibrous meningioma with granular nuclei and eosinophilic-rich cytoplasm, but mainly consisted of mucin-rich cells which were positive for periodic acid-Schiff (PAS) stain. This chordoid area formed about $75 \%$ of the tumor, and was intermixed with small areas of conventional meningioma such as fibrous meningioma. Lymphoplasmacellular infiltrates were present surrounding the tumor margin. No nuclear pleomorphism including mitosis or necrosis was found (Fig. 3A).

Immunohistochemical staining revealed typical membranous staining of meningioma for epithelial membrane antigen (EMA) in focal areas and diffuse
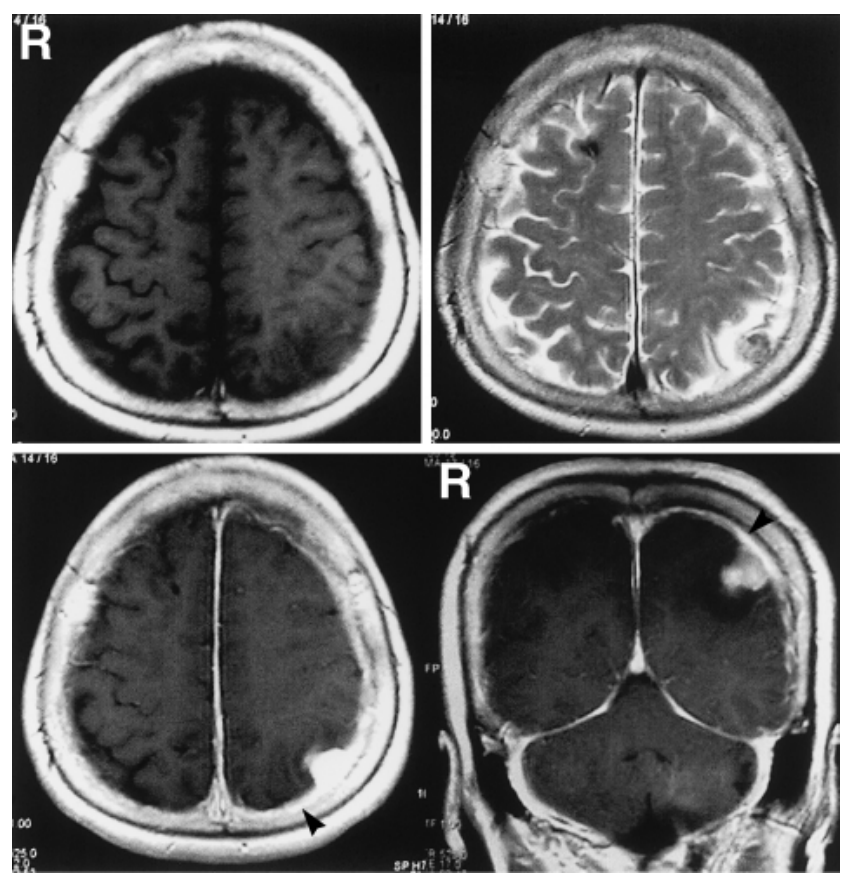

Fig. 2 Magnetic resonance images showing a mass in the left parietal lobe as homogeneously isointense on the $T_{1}$-weighted image (upper left) and homogeneously hyperintense on the $\mathrm{T}_{2}$-weighted image (upper right). Axial and coronal $T_{1}$-weighted images after intravenous injection of gadoliniumdiethylenetriaminepenta-acetic acid (lower row) showing intense, uniform enhancement, with an associated dural tail sign (arrowhead).

cytoplasmic staining for vimentin (Fig. 3B). No tumor cells expressed S-100 protein (Fig. 3C), glial fibrillary acidic protein (GFAP), or cytokeratin (Fig. 3D). All these findings were consistent with a diagnosis of chordoid meningioma. The MIB-1 labeling index was $2.3 \%$.

\section{Discussion}

Sixty-five cases of chordoid meningioma have been reported including our case ca,6,8,10-12,14,17-20,22-25) $^{4}$ (Table 1). Ten patients aged from 8 to 55 years (mean 28.2 years) presented with systemic disease such as Castleman's disease. The remaining 55 patients without systemic disease were aged from 8 to 77 years (mean 39.01 years) with a slight female predominance (male:female ratio 1:1.32). The association of the systemic disease may be limited to chordoid meningioma in children, with no relationship with systemic or hematological disease in adults. ${ }^{4}$ Locations of the tumors were not unusual compared with meningioma: 57 cases were supratentorial 
tumors and the remaining eight cases were infratentorial and spinal tumors.

In the present case, thick and wide so-called "dural tail sign" was revealed by $\mathrm{T}_{1}$-weighted MR imaging with Gd-DTPA. "Dural tail sign" may be caused by either direct tumor invasion or reactive changes of connective tissue and vessels adjacent to
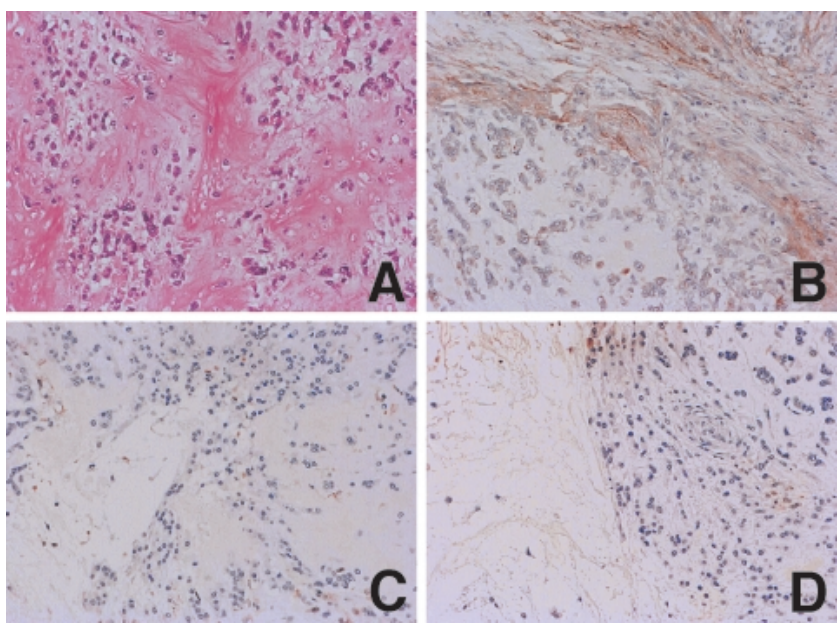

Fig. 3 Photomicrographs of the surgical specimen showing a lobulated area of eosinophilic tumor cells in mucoid stroma with a chordoma-like appearance (A: hematoxylin and eosin stain, $\times 200$ ), and the epithelioid cells positive for epithelial membrane antigen (B: $\times 200$ ), but no positive staining for $S-100$ protein $(\mathrm{C}: \times 200)$ or glial fibrillary acidic protein $(\mathrm{D}: \times 200)$. the dura-based tumor. ${ }^{9,21)}$ The intralesional hyperintensity and surrounding edema may reflect deep lymphoplasmacellular infiltration. ${ }^{12)}$ Lymphoplasmacellular infiltration in chordoid meningioma is probably strongly related to this thick and wide dural tail sign.

Histologically, these tumors consist of spindle or epithelial cells forming chordoma-like clusters scattered in a myxoid matrix. Mucin-rich chordoid areas comprise more than $50 \%$ of the tumors in the majority of cases. ${ }^{4)}$ The myxoid matrix consists of acid mucin and stains with Alcian blue at $\mathrm{pH} 2$, mucicarmine, and PAS. ${ }^{18)}$ Two-thirds of adult tumors show mild-to-moderate lymphoplasmacellular inflammatory infiltrate. ${ }^{1,4,12,15)}$ Such histological features are distinctive, but the differential diagnosis includes chordoma, myxoid chondrosarcoma, and chordoid glioma.

Immunohistochemical methods can help to establish the differential diagnosis and to characterize chordoid meningioma. Chordoid meningioma cells are usually positive for vimentin and EMA, and occasionally positive for S-100 protein and cytokeratin, but negative for GFAP..$^{4,12,15,23)}$

Chordomas are usually located in the midline of central nervous systems and show strong staining for cytokeratin and EMA. ${ }^{16)}$ Myxoid chondrosarcoma has not been reported in the central nervous system, and is usually positive for S-100 protein. ${ }^{5)}$ Chordoid glioma is usually located in the third ventricle and strongly positive for GFAP. ${ }^{2)}$

The pathogenesis of the tumor is unclear at present, but may involve secondary degenerative

Table 1 Reported cases of chordoid meningioma

\begin{tabular}{|c|c|c|c|c|c|c|c|c|}
\hline Author (Year) & $\begin{array}{l}\text { No. of } \\
\text { cases }\end{array}$ & Male & Female & Age $^{*}$ (yrs) & $\begin{array}{l}\text { Supra- } \\
\text { tentorium }\end{array}$ & $\begin{array}{l}\text { Other } \\
\text { location }\end{array}$ & Systemic disease (cases) & $\begin{array}{c}\text { Ki67/MIB-1 } \\
\text { labeling } \\
\text { index }(\%)\end{array}$ \\
\hline Kepes et al. (1988) ${ }^{11)}$ & 7 & 3 & 4 & $8-19(14.8)$ & 7 & 0 & $\begin{array}{l}\text { anemia (7), } \\
\text { dysgammaglobulinemia (1) }\end{array}$ & NR \\
\hline Glasier et al. (1993) ${ }^{8)}$ & 1 & 0 & 1 & 15 & 0 & 1 & NR & NR \\
\hline Zuppan et al. (1994) ${ }^{25)}$ & 1 & 0 & 1 & 10 & 1 & 0 & none & NR \\
\hline Kobata et al. (1998) ${ }^{12)}$ & 1 & 0 & 1 & 15 & 1 & 0 & anemia (1) & NR \\
\hline Kajiwara et al. (1999) ${ }^{10)}$ & 1 & 1 & 0 & 52 & 1 & 0 & NR & NR \\
\hline Couce et al. (2000) ${ }^{4)}$ & 42 & 20 & 22 & $12-77(47.4)$ & 37 & 5 & none & NR \\
\hline Yano et al. $(2000)^{23)}$ & 1 & 0 & 1 & 44 & 1 & 0 & none & 1 \\
\hline Mori et al. $(2001)^{17)}$ & 1 & 0 & 1 & 62 & 1 & 0 & none & NR \\
\hline Lee et al. $(2001)^{14)}$ & 1 & 0 & 1 & 55 & 1 & 0 & dysgammaglobulinemia (1) & 10 \\
\hline de Tella et al. $(2003)^{6)}$ & 2 & 2 & 0 & $19-52(35.5)$ & 2 & 0 & NR & NR \\
\hline Varma et al. $(2003)^{22)}$ & 2 & 1 & 1 & $20-33(26.5)$ & 2 & 0 & none & NR \\
\hline Yeon et al. $(2003)^{24)}$ & 1 & 1 & 0 & 33 & 1 & 0 & none & few \\
\hline Murali and Ng (2004) $)^{18)}$ & 1 & 0 & 1 & 61 & 0 & 1 & NR & NR \\
\hline Ozen et al. $(2004)^{19)}$ & 1 & 0 & 1 & 48 & 1 & 0 & none & 0.20 \\
\hline Soo et al. $(2004)^{20)}$ & 1 & 0 & 1 & 60 & 0 & 1 & none & NR \\
\hline Present case & 1 & 0 & 1 & 69 & 1 & 0 & none & 2.30 \\
\hline
\end{tabular}

*Range (mean). NR: not recorded. 
change in a primary meningeal tumor.,412) In the present case, growth of a new tumor may support the hypothesis that the origin is secondary degeneration in a primary meningeal tumor.

In the previous reports, Ki67/MIB-1 labeling index was in the range of $0.2-10 \%$. In one series, $40 \%$ of the tumors recurred, mainly related to incomplete removal. ${ }^{4)}$ However, the relationship between the recurrence and the MIB-1 labeling index was not described. In our case, MIB-1 labeling index was low at $2.3 \%$, which did not correspond to the malignant potential of the tumor. However, this tumor grew in the short term. The rapid growth of this tumor suggested close follow up is necessary, despite the total removal and the low MIB-1 labeling index.

In conclusion, chordoid meningiomas are histologically similar to chordoid neoplasm. Immunohistochemical staining is very helpful for the differential diagnosis. Surgery should be performed because extra-axial tumor with such neuroimaging presentation might be chordoid meningioma.

\section{References}

1) Berger PC, Scheithauer BW: Tumors of meningothelial cells, in Berger PC, Scheithauer BW (eds): Atlas of Tumor Pathology: Tumors of the Central Nervous System, ser 3, fasc 10. Washington, DC, Armed Forces Institute of Pathology, 1994, pp 259-283

2) Brat DJ, Scheithauer BW, Staugaitis SM, Cortez SC, Brecher K, Burger PC: Third ventricular chordoid glioma: a distinct clinicopathologic entity. $\mathrm{J} \mathrm{Neu-}$ ropathol Exp Neurol 57: 283-290, 1998

3) Connors $\mathrm{MH}$ : Growth and maturation arrest, hypochromic anemia and hyperglobulinemia associated with a brain tumor. West J Med 133: 160-163, 1980

4) Couce ME, Aker FV, Scheithauer BW: Chordoid meningioma: a clinicopathologic study of 42 cases. Am J Surg Pathol 24: 899-905, 2000

5) Cybulski GR, Russel EJ, D’Angelo CM, Bailey OT: Falcine chondrosarcoma: case report and literature review. Neurosurgery 16: 412-415, 1985

6) de Tella OI Jr, Herculano MA, Prandini MN, Stavile JN, Bonatelli Ade P: Chordoid meningioma: report of two cases. Arq Neuropsiquiatr 61: 91-94, 2003

7) Dimand RJ, Connors MH, Lazerson J: Headaches and growth arrest in an adolescent. Hosp Pract (Off Ed) 20: 50, 56-57, 60, 1985

8) Glasier CM, Husain MM, Chadduck W, Boop FA: Meningiomas in children: MR and histopathologic findings. AJNR Am J Neuroradiol 14: 237-241, 1993

9) Goldsher D, Litt AW, Pinto RS, Bannon KR, Kricheff II: Dural "tail" associated with meningiomas on Gd-DTPA-enhanced MR images: characteristics, differential diagnostic value, and possible implica- tions for treatment. Radiology 176: 447-450, 1990

10) Kajiwara Y, Kodama Y, Hotta T, Kohno H, Taniguchi E, Yamasaki F, Katayama S, Yamane M: [A case of chordoid meningioma]. No Shinkei Geka 27: 947-951, 1999 (Jpn, with Eng abstract)

11) Kepes JJ, Chen WY, Connors MH, Vogel FS: “Chordoid" meningeal tumors in young individuals with peritumoral lymphoplasmacellular infiltrates causing systemic manifestations of the Castleman syndrome. A report of seven cases. Cancer 62: 391-406, 1988

12) Kobata $H$, Kondo A, Iwasaki $K$, Kusaka $H$, Ito $H$, Sawada S: Chordoid meningioma in a child. Case report. J Neurosurg 88: 319-323, 1998

13) Lantos PV, VandenBerg SR, Kleihues P: Tumours of the nervous system, in Graham DI, Lantos PL (eds): Greenfield's Neuropathology, ed 6. London, Arnold, 1996, pp 583-879

14) Lee DK, Kim DG, Choe G, Chi JG, Jung HW: Chordoid meningioma with polyclonal gammopathy. Case report. J Neurosurg 94: 122-126, 2001

15) Louis DN, Scheithauer BW, Budka H, von Deimling A, Kepes JJ: Meningiomas, in Kleihues P, Cavenee WK (eds): Pathology \& Genetics of Tumours of the Nervous System. Lyon, IARC Press, 2000, pp 176-189

16) Mierau GW, Weeks DA: Chordoid chordoma. Ultrastruct Pathol 11: 731-737, 1987

17) Mori S, Oka K, Hakozaki H, Soga Y, Hayano M, Oka T, Nakazato Y, Mori N: Chordoid meningioma. A case report. Pathol Res Pract 197: 515-519, 2001

18) Murali R, Ng T: Chordoid meningioma masquerading as chordoma. Pathology 36: 198-201, 2004

19) Ozen O, Sar A, Atalay B, Altinors N, Demirhan B: Chordoid meningioma: rare variant of meningioma. Neuropathology 24: 243-247, 2004

20) Soo MY, Ng T, Gomes L, Da Cruz M, Dexter M: Skull base chordoid meningioma: imaging features and pathology. Australas Radiol 48: 233-236, 2004

21) Tokumaru A, O'uchi T, Eguchi T, Kawamoto S, Kokubo T, Suzuki M, Kameda T: Prominent meningeal enhancement adjacent to meningioma on Gd-DTPA-enhanced MR images: histopathologic correlation. Radiology 175: 431-433, 1990

22) Varma DR, Rao BR, Parameswaran S, Gupta AK, Joseph S, Radhakrishnan VV: Chordoid meningioma: a report of two cases. Neurol India 51: 522-524, 2003

23) Yano H, Shinoda J, Hara A, Shimokawa K, Sakai N: Chordoid meningioma. Brain Tumor Pathol 17: 153-157, 2000

24) Yeon JY, Lee JI, Kim JH, Suh YL: Chordoid meningioma: a case report. J Korean Med Sci 18: 768-771, 2003

25) Zuppan CW, Liwnicz BH, Weeks DA: Meningioma with chordoid features. Ultrastruct Pathol 18: 29-32, 1994

Address reprint requests to: T. Mitsuhashi, M.D., Department of Neurosurgery, Tokyo Metropolitan Hiroo General Hospital, 2-34-10 Ebisu, Shibuya-ku, Tokyo 150-0013, Japan. 